\title{
O ensino da descrição nos cursos de Arquivologia da Universidad de la República e da Universidade Federal de Santa Catarina
}

\author{
Rafael Oda \\ Universidade Federal de Santa Catarina, Departamento de Ciência da Informação, Programa de \\ Pós-Graduação em Ciência da Informação, Florianópolis, SC, Brasil \\ rafaeloda@outlook.com.br
}

Miriam Figueiredo Vieira da Cunha

Universidade Federal de Santa Catarina, Departamento de Ciência da Informação, Programa de Pós-Graduação em Ciência da Informação, Florianópolis, SC, Brasil vieiradacunha.miriam@gmail.com

DOI: https://doi.org/10.26512/rici.v13.n1.2020.27067

Recebido/Recibido/Received: 2019-09-06

Aceitado/Aceptado/Accepted: 2019-10-22

Resumo: O presente artigo apresenta uma comparação da unidade curricular de Descrição Documental na Universidad de la República (UdelaR), Uruguai e da disciplina de Descrição Arquivística na Universidade Federal de Santa Catarina (UFSC), Brasil. É resultado de uma visita realizada na UdelaR durante o período de intercâmbio acadêmico no primeiro semestre do ano de 2017. Ao se comparar o ensino da disciplina nas duas universidades, através da análise dos planos de ensino nos primeiros semestres de 2017 e de 2019, foi possível observar que o ensino da disciplina diverge em alguns aspectos, mas possui similaridades quanto ao seu objetivo. Conclui que a descrição, como uma das sete funções arquivísticas e parte da gestão documental, traz diversos benefícios e, para sua realização, múltiplos desafios. E para tal o arquivista demanda por um conjunto de competências e habilidades que podem ser desenvolvidas durante a graduação, assim, estudos como este auxiliam no diagnóstico do ensino da disciplina.

Palavras-chave: arquivologia. descrição arquivística. descrição documental. Uruguai. Brasil.

\section{The teaching of description in Archivology courses of Universidad de la República and Universidade} Federal de Santa Catarina

Abstract: This paper presents a comparison of the curricular unit of Documentary Description at the University of the Republic (UdelaR), Uruguay and of the discipline of Architectural Description at the Federal University of Santa Catarina (UFSC), Brazil. It is the result of a visit to UdelaR during the academic exchange period in the first semester of 2017. By comparing the teaching of the subject in the two universities, by analyzing the subject's plans in the first semesters of 2017 and 2019, it was observed that the teaching of the subject differs in some respects but has similarities as to its purpose. It concludes that the description, as one of the seven archival functions and part of the document management, brings several benefits and, for its accomplishment, multiple challenges. And for this the archivist demands for a set of competences and skills that can be developed during the undergraduate, thus, studies like this help in the diagnosis of the teaching of the discipline.

Keywords: Archival Science. archival description. documentary description. Uruguay. Brazil.

La enseñanza de la descripción en los cursos de Archivología de la Universidad de la República e de la Universidade Federal de Santa Catarina

Resumen: Este artículo presenta una comparación de la unidad curricular de Descripción Documental de la Universidad de la República (UdelaR), Uruguay y de la disciplina de Descripción Arquitectónica de la 
Universidad Federal de Santa Catarina (UFSC), Brasil. Es el resultado de una visita a UdelaR durante el período de intercambio académico en el primer semestre de 2017. Al comparar la enseñanza de la disciplina en las dos universidades, al analizar los planes de la asignatura en el primer semestre de 2017 y 2019, se observó que la disciplina diverge en algunos aspectos, pero tiene similitudes en cuanto a su propósito. Concluye que la descripción, como una de las siete funciones de archivo y parte de la gestión de documentos, trae varios beneficios y, para su realización, múltiples desafíos. Y para esto, el archivero exige un conjunto de competencias y habilidades que se puedan desarrollar durante la licenciatura, por lo tanto, estudios como este ayudan en el diagnóstico de la enseñanza de la disciplina.

Palabras-clave: Archivología. descripción archivística. descripción documental. Uruguay. Brasil.

\section{Introdução}

Aqueles que ingressam em uma graduação deparam-se com as muitas expectativas e possibilidades. Uma das possibilidades que as instituições de ensino superior proporcionam é a realização de intercâmbios acadêmicos. A Asociación de Universidades Grupo Montevideo (AUGM) é uma organização voltada para o vínculo entre universidades e oferece oportunidades de intercâmbio para docentes e discentes das universidades participantes.

O intercâmbio foi realizado na Universidad Nacional de Mar del Plata (UNMdP), Argentina, entre março e julho de 2017. No plano de atividades constava a identificação de unidades de informação nas cidades visitadas. O contato com a Universidad de la República (UdelaR), localizada em Montevidéu, ocorreu como resultado dessas atividades.

Em uma visita ao Museo y Archivo Histórico Cabildo na capital uruguaia, no dia 27 de abril de 2017, a arquivista Virginia Luzardo - funcionária da instituição e professora universitária apresentou o arquivo, nos convidou para conhecer a UdelaR e participar de uma aula da unidade curricular de Descrição Documental, do curso de Arquivologia. Nesse sentido, surgiu a ideia desse artigo que analisa e compara o ensino da descrição nos cursos de Arquivologia das duas universidades.

\section{A descrição arquivística}

No que diz respeito à Arquivologia a literatura especializada entende como sete as funções arquivísticas: produção, classificação, avaliação, descrição, aquisição, difusão e preservação. E para que haja uma gestão documental eficaz nos arquivos e instituições arquivísticas, a realização dessas atividades é fundamental.

A Descrição Arquivística é o "conjunto de procedimentos que levam em conta elementos formais e de conteúdo dos documentos para a elaboração de instrumentos de pesquisa". (ARQUIVO NACIONAL, 2005, p. 67). A descrição visa identificar documentos, com o objetivo de gerar um instrumento de pesquisa que permita a localização ou recuperação da informação. 
Lopez (2002, p. 10) afirma que esses instrumentos "são as ferramentas utilizadas para descrever um arquivo, ou parte dele, tendo a função de orientar a consulta e determinar com exatidão quais são e onde estão os documentos". Esses instrumentos auxiliam na atuação dos profissionais do arquivo, permitindo um maior controle sobre o acervo documental. Permite ainda que os usuários tenham uma maior aproximação com os documentos e sua localização no acervo. Entre os instrumentos de pesquisa, destacados pelo autor estão os guias, inventários, catálogo e índices.

A Descrição Arquivística é uma das funções mais complexas da área. Essa disciplina vem sendo objeto de discussões e normalização desde a década de 90 . Entre as normas que tratam da descrição estão: a Norma Geral Internacional de Descrição Arquivística - ISAD (G), de 2000; a Norma Internacional de Registro de Autoridade Arquivística para Entidades Coletivas, Pessoas e Famílias - ISAAR (CPF), de 2004; a Norma Brasileira de Descrição Arquivística - NOBRADE, de 2006; a Norma Internacional para Descrição de Funções - ISDF, de 2007; e a Norma Internacional para Descrição de Instituições com Acervo Arquivístico - ISDIAH, de 2008.

Uma descrição padronizada possui diversas vantagens, entre as quais uma melhor qualidade ao trabalho técnico, economia dos recursos e otimização das informações recuperadas. A normalização deste processo possibilita ao pesquisador um melhor uso dos instrumentos de pesquisa. (NOBRADE, 2006, p. 10).

Algumas normas auxiliam o estabelecimento de padrões e métodos para a elaboração de instrumentos de pesquisa. Neste sentido, a ISAD (G) representa um marco no que diz respeito à descrição, passando a orientar essa prática:

O objetivo da descrição arquivística é identificar e explicar o contexto e o conteúdo de documentos de arquivo a fim de promover o acesso aos mesmos. Isto é alcançado pela criação de representações precisas e adequadas e pela organização dessas representações de acordo com modelos predeterminados. Processos relacionados à descrição podem começar na ou antes da produção dos documentos e continuam durante sua vida. Esses processos permitem instituir controles intelectuais necessários para tornar confiáveis, autênticas, significativas e acessíveis descrições que serão mantidas ao longo do tempo. (CONSELHO INTERNACIONAL DE ARQUIVOS, 2000, p. 11).

A descrição é geralmente relacionada aos arquivos permanentes. Os processos relacionados com essa disciplina, de acordo com a ISAD (G) iniciam durante a produção documental ou antes. Lopes (1996) afirma que através do viés da arquivística integrada, a descrição tem inicio com o processo de classificação, perpassa a avaliação documental e se aprofunda no desenvolvimento dos instrumentos de pesquisa na fase permanente, abarcando todo o ciclo documental. 
A elaboração de um instrumento de pesquisa traz diversas vantagens. A descrição é uma das funções arquivísticas mais complexas, sendo objeto de padronização por diversas normas. Segundo Duff (2016, p. 174) o serviço de referência possui muitos desafios:

1) Os arquivos não possuem índices e nem instrumentos de pesquisas para oferecerem fácil acesso às fontes; 2 ) Os arquivos guardam pilhas de material fechado e os documentos não são navegáveis; 3) Os arquivos são arranjados e descritos de acordo com a proveniência e não pelos assuntos que os usuários buscam; 4) Os arquivos talvez não possuam coerência, o que torna a busca mais complexa; 5) As ferramentas de referência própria para arquivos são muito limitadas e busca de informações nos arquivos muitas vezes é inferencial e baseada no que os arquivistas sabem sobre os produtos dos documentos e não sobre os temas que ele contém; 6) Os usuários não sabem como realizar pesquisas utilizando fontes primárias; 7) Os usuários têm menos experiência com arquivo do que com biblioteca; 8) A interação entre os arquivistas de referência e os usuários apresenta maiores demandas do que entre os bibliotecários de referência e os usuários; 9) Normalmente, os arquivistas que processaram, arranjaram e descreveram os documentos são os mesmos que ajudam os usuários a consultá-los.

À luz desses desafios, o arquivista de referência, deve ter um conjunto de habilidades e competências. Exercitar e desenvolver essas habilidades e competências é parte da formação deste profissional. Neste sentido, esse estudo pretende contribuir para o diagnóstico dos planos de ensino relativos a essa disciplina nos cursos de Arquivologia na Universidad de la República e na Universidade Federal de Santa Catarina.

\section{Aspectos metodológicos}

A presente pesquisa é de natureza aplicada, de abordagem qualitativa e de acordo com seus objetivos se classifica como descritiva. A pesquisa científica aplicada é aquela que busca fazer uso de conhecimentos já estruturados, objetivando o diagnóstico de determinada situação ou contexto, possibilitando a busca por melhorias de um processo ou atividade.

A abordagem da pesquisa teve como enfoque a investigação de caráter subjetivo do ensino da descrição nas duas instituições de ensino superior, considerando suas particularidades. E quanto a seus objetivos, buscou descrever o objeto de estudo e suas características, visando identificar as semelhanças e diferenças nos planos de ensino.

A coleta dos planos de ensino do ano 2017 ocorreu de forma presencial através da realização de intercâmbio e viagem realizada a Montevidéu, entre os dias 26 de abril e 1 de maio de 2017, em que foi possível conhecer a Universidad de la República (UdelaR), a convite da professora da disciplina de Descrição Documental do curso de Arquivologia, Virginia Luzardo. Os planos de ensino de 2019 foram coletados através das páginas web dos cursos de graduação em Arquivologia das universidades, a análise dos documentos ocorreu posteriormente e os resultados são apresentados a seguir. 


\section{0 ensino da descrição documental na UdelaR}

O curso de Arquivologia no Uruguai, de acordo com Petroccelli (2017, p. 215), iniciou em 1983, aproximadamente quarenta anos após a criação do curso de Biblioteconomia. 0 curso de Arquivologia tinha, no seu inicio, dois anos de duração. Em 1987, passou a três anos.

O currículo desse curso sofreu alterações em 1993 e em 2009. Neste último ano, com transformações estruturais e organizacionais, a Escola Universitária de Biblioteconomia e Ciências Afins “Eng. Federico E. Capurro" - responsável até então pela formação de arquivistas e bibliotecários - juntamente com a Licenciatura em Ciências da Comunicação (LICCOM) elaboraram um projeto para a criação de uma Faculdade, integrando os cursos. Com esse processo, a grade curricular foi atualizada em 2012, quando o curso de Arquivologia passou a ter 4 anos de duração, divididos em 8 fases com 360 créditos (cada crédito tem uma equivalência de 15 horas), sendo exigido um trabalho de conclusão de curso para receber o título de Licenciado em Arquivologia. (PETROCCELLI, 2017).

De acordo com essa autora, o Conselho Diretivo Central da Universidad de la República aprovou a criação da Faculdade de Informação e Comunicação em 2013. Em fevereiro de 2017, foi inaugurado o novo prédio de $8.500 \mathrm{~m}^{2}$, localizado no bairro Parque Rodó, em Montevidéu. Nesta época, essa faculdade tinha cerca de 4000 estudantes, 200 professores e 80 funcionários.

Em abril de 2017, fizemos uma visita a essa Instituição, quando conhecemos a biblioteca, o arquivo e as salas de aula. Neste período, a biblioteca e o arquivo passavam por uma reorganização. Esse investimento possibilitou a compra de mobiliário adequado, acondicionamento acústico e térmico, bem como estrutura física para atender estudantes, professores e pesquisadores. $\mathrm{O}$ armazenamento documental é realizado em caixas poliondas e em arquivo deslizante, com climatização e estrutura adequadas. A instituição tem ainda diversos laboratórios, sendo um deles para a prática de restauração documental.

A Faculdade de Comunicação e Informação, conta atualmente com três cursos de graduação: Arquivologia, Biblioteconomia e Comunicação, e um mestrado em Informação e Comunicação.

Conforme relatado anteriormente, no ano de 2017, assistimos uma aula da unidade curricular de Descrição Documental - nomenclatura utilizada pela instituição, a convite da professora Virginia Luzardo. A unidade, parte integrante do currículo do curso de Licenciatura em Arquivologia, de modalidade presencial, é ministrada no período noturno. Tinha como prérequisitos as unidades curriculares de Introdução a Arquivologia e a Ciência da Informação, Organização Documental e Gestão Documental I, integrando o ciclo intermediário do curso. 
Era ministrada no 3 semestre, com 10 créditos (150 horas/aula). O ciclo intermediário, em que a unidade curricular é ministrada, é considerado como a:

Etapa em que se centram os conteúdos disciplinares e profissionais, aprofundando a análise e reflexão crítica sobre o objeto de estudo e sua aplicação na realidade. Com enfoque na interdisciplinaridade, na articulação e na integração das funções e na flexibilidade e mobilidade horizontal (dentro e fora do serviço). Neste momento o estudante constrói sua própria trajetória formativa com orientação dos docentes. (UdelaR, tradução nossa, 2019).

O ciclo inicial é introdutório; o intermediário busca o aprofundamento dos estudos da área; e o ciclo de graduação (ou final) direciona a inserção do aluno na profissão, assim como, sua formação continuada e seu ingresso na pós-graduação. (UdelaR, 2019). A partir dessa análise, verifica-se que a Descrição Documental demanda um olhar crítico sobre os documentos para sua realização, articulação e integração, tendo como produto final o instrumento de pesquisa.

Os objetivos da descrição da UdelaR, eram em 2017:

Proporcionar os fundamentos teóricos e gerais do processo de Descrição Arquivística, estabelecendo as correlações existentes com os demais processos técnicos; Reconhecer a importância da normalização da descrição para a elaboração de instrumentos de descrição em arquivos; Estabelecer procedimentos unificados na representação e recuperação do conteúdo da documentação para os usuários reais, potenciais e remotos e; Adquirir a formação requerida para o desenvolvimento da Descrição documental desde uma visão sistemática do programa de Gestão Documental organizacional de uma forma eficiente. (UdelaR, tradução nossa, 2017, p. 1).

Os conteúdos da unidade curricular eram divididos em quatro unidades apresentadas a seguir:

Quadro 1 - Conteúdos programáticos da unidade curricular de Descrição Documental

\begin{tabular}{|l|l|l|}
\hline \multicolumn{1}{|c|}{ UNIDADE } & \multicolumn{1}{|c|}{ CONTEÚDO } & \multicolumn{1}{c|}{ OBJETIVO } \\
\hline Inicial & Apresentação do Curso & $\begin{array}{l}\text { Conhecer os objetivos da disciplina, os conteúdos, } \\
\text { a metodologia, os critérios de aprovação e } \\
\text { avaliação; indicar os parâmetros e condições para e } \\
\text { elaboração e entrega dos trabalhos; definir as } \\
\text { regras de convivência em sala e; garantir aos } \\
\text { estudantes o direito de se beneficiar do processo } \\
\text { educativo de forma plena. }\end{array}$ \\
\hline 1 & $\begin{array}{l}\text { Análise documental } \\
\text { necessidade na área da } \\
\text { informação }\end{array}$ & $\begin{array}{l}\text { Conceituar a Organização do Conhecimento sobre } \\
\text { o saber acumulado nos documentos de arquivo; } \\
\text { mostrar a incidência da descrição documental na } \\
\text { organização de uma unidade de informação; } \\
\text { aprofundar a análise das características } \\
\text { documentais e; determinar sistemas documentais } \\
\text { de indexação para a recuperação. }\end{array}$ \\
\hline 2 & Normalização da descrição & $\begin{array}{l}\text { Criar padrões para uma política de descrição } \\
\text { normalizada e analisar as distintas normas de }\end{array}$ \\
\hline
\end{tabular}




\begin{tabular}{|l|l|l|}
\hline \multirow{3}{*}{3} & & descrição aplicadas. \\
\hline & Instrumentos de pesquisa & $\begin{array}{l}\text { Analisar as distintas terminologias existentes; } \\
\text { proporcionar os conhecimentos necessários para o } \\
\text { planejamento e elaboração dos instrumentos de } \\
\text { pesquisa; apresentar as técnicas de descrição } \\
\text { documental em suportes textuais e determinar os } \\
\text { instrumentos que devem ser utilizados nos } \\
\text { arquivos. }\end{array}$ \\
\hline
\end{tabular}

Fonte: Adaptado do plano de ensino de Descrição Documental da UdelaR, 2017.

A unidade inicial situava o aluno na disciplina e introduzia a descrição. A primeira unidade conceituava a descrição, bem como seus propósitos e o planejamento de um programa descritivo, os atributos dos documentos e a linguagem documental.

A segunda unidade apresentava e discutia as generalidades, as estruturas e os elementos essenciais das principais normas de descrição: a Norma Geral Internacional de Descrição Arquivística - ISAD (G); a Normal Internacional de Registro de Autoridade Arquivística para Entidades Coletivas, Pessoas e Famílias - ISAAR (CPF); a Norma Internacional para Descrição de Funções - ISDF; a Norma Internacional para Descrição de Instituições com Acervo Arquivístico - ISDIAH e; a Norma Uruguaia de Descrição Arquivística - NUDA.

A terceira unidade tinha como foco os instrumentos de pesquisa, o marco conceitual e os tipos de instrumentos, entre eles: registro, índice, folha de remissão, inventário, guia e catálogo e a descrição em outros suportes.

A unidade curricular era teórico-prática com um aprendizado ativo, reflexivo e criativo, com diversas técnicas didáticas, entre as quais: teórico-conceitual, práticas em geral, estudos de caso, debates, equipes de trabalho e observação direta. A avaliação final ocorria com exames parciais e outras atividades. A presença mínima exigida para a aprovação era de $70 \%$. (UdelaR, 2017)

A área da informação vem passando por múltiplas transformações, transformações essas que afetam os currículos. O plano de ensino da unidade curricular em 2019, conta com 8 créditos (120 horas/aula). Embora tenha sofrido redução de sua carga horária, os conteúdos programáticos se mantiveram com exceção da unidade três que tem atualmente um módulo de Modelo Conceitual em Descrição Arquivística (RiC-CM). Com o novo currículo, a carga horária passou de 150 a 120 horas, sendo 60 horas de aula teórico-práticas, 20 de práticas externas, 35 de trabalhos domiciliares e 5 de preparação expositiva.

Os pré-requisitos para cursar a unidade curricular e a presença mínima em aula se mantiveram. No entanto definiu-se uma média oito para a aprovação dos exames parciais para a aprovação final. Foram criadas outras formas de avaliação como: controle de leituras, 
trabalhos extraclasse, participação em aula, apresentação de seminários, atividades práticas e exames parciais.

O Uruguai tem algumas leis que regulamentam o acesso à informação: Lei no 18.220, de 20 de dezembro de 2007, dispõe sobre o Sistema Nacional de Arquivos e a Lei no 18.381, de 17 de outubro de 2008, dispõe sobre o direito de acesso à informação pública. A descrição é um dos processos de tratamento intelectual dos documentos de arquivo, parte da gestão documental, que auxilia o acesso à informação e atende às demandas sociais. Embasada por diversas normas nacionais e internacionais, demanda um conhecimento aprofundado de conceitos, métodos e padrões, ministrados no ensino dessa função.

Em junho de 2019, a profissão de Arquivista no Uruguai foi reconhecida e regulamentada. $O$ exercício da Arquivologia, naquele país permite:

A) Planejar, projetar, administrar, avaliar, controlar e gerenciar tecnicamente os documentos de arquivo, em seus diferentes suportes. B) Identificar, produzir, organizar, descrever, avaliar, selecionar, realizar diagnósticos, preservar e custodiar os documentos e, em geral, levar realizar as atividades que visam o desenvolvimento da gestão documental [...] (URUGUAI, tradução nossa, 2019, p. 2).

Neste sentido, a atuação dos arquivistas nesse país é definida por lei. Desta forma, é essencial que o profissional esteja capacitado para tal. Por essa razão é importante que a graduação tenha uma unidade curricular com enfoque na Descrição Documental e que esteja em sintonia, com as transformações sociais, econômicas, políticas e tecnológicas do país.

\section{0 ensino da descrição arquivística na UFSC}

A regulamentação da profissão de arquivista no Brasil, é de 4 de julho 1978, através da Lei no 6.546, que dispõe sobre a regulamentação desse profissional e do Técnico de Arquivo. Entre as atribuições do arquivista descritas nessa lei, estão o "planejamento, organização e direção de serviços de Arquivo" e a "orientação quanto à classificação, arranjo e descrição de documentos". Também é determinado por lei, o conhecimento da Descrição Documental necessário para a sua atuação profissional. (BRASIL, 1978).

O curso de Arquivologia na Universidade Federal de Santa Catarina foi criado em 2009. A primeira turma iniciou em 2010, com uma oferta de sessenta vagas, divididas em dois semestres. A criação do curso foi motivada pela demanda catarinense por profissionais capazes de atuar com o processo de gestão documental. O curso tem 4 anos de duração, divididos em 8 semestres com 160 créditos (cada crédito equivale 18 horas), totalizando 2.880 h/a. O projeto pedagógico previa 136 créditos de disciplinas obrigatórias e 24 de disciplinas optativas. (UFSC, 2010). 
Entre os objetivos específicos do curso estavam, segundo o projeto pedagógico da UFSC (2010, p. 19), o de "preparar o aluno para promoção do conhecimento teórico-prático direcionado às atividades de produção, análise, classificação, avaliação, descrição, preservação, recuperação, mediação, disseminação e uso da informação arquivística". A disciplina de Descrição Arquivística existe desde a criação do curso, e é considerada indispensável para a formação dos arquivistas. A disciplina integrava o 3ำ ano da graduação e era ministrada no 5o semestre do curso.

A disciplina CIN 7136 - Descrição Arquivística, contava com 4 créditos (72 horas/aula). Segundo sua ementa: "aborda aspectos teóricos, metodológicos e princípios norteadores da descrição arquivística. Trata dos elementos, níveis e dos instrumentos de pesquisa. Normas e padrões de descrição arquivística. Introdução a indexação e linguagens documentárias. Resumos e índices. Aplica a prática da descrição arquivística". (UFSC, 2017, p. 1)

A disciplina de modalidade presencial e ministrada no período matutino, com 72 horas/aula sendo 31 de aulas teóricas e 41 de práticas. Seu objetivo era "ao final do semestre, os alunos deverão ser capazes de dominar as bases teóricas e metodológicas da descrição, assim como, sua prática". (UFSC, 2017, p. 1).

O quadro a seguir mostra a relação entre os objetivos específicos e os conteúdos programáticos da disciplina:

Quadro 2 - Conteúdos programáticos da disciplina de Descrição Arquivística

\begin{tabular}{|c|c|}
\hline OBJETIVO ESPECÍFICO & CONTEÚDO PROGRAMÁTICO \\
\hline $\begin{array}{l}\text { Conhecer os fundamentos teóricos, } \\
\text { metodológicos e princípios norteadores da } \\
\text { descrição arquivística; }\end{array}$ & $\begin{array}{l}\text { Descrição arquivística: conceituação, fundamentos } \\
\text { teóricos, metodológicos e princípios norteadores; }\end{array}$ \\
\hline $\begin{array}{l}\text { Conhecer os elementos, níveis e } \\
\text { instrumentos de pesquisa aplicados à } \\
\text { descrição arquivística; }\end{array}$ & $\begin{array}{l}\text { Representação descritiva de documentos e conjuntos } \\
\text { documentais; elementos e áreas de descrição; }\end{array}$ \\
\hline $\begin{array}{l}\text { Conhecer as normas e padrões da descrição } \\
\text { arquivística; }\end{array}$ & $\begin{array}{l}\text { Normas e padrões da descrição arquivística: ISAD (G), } \\
\text { NOBRADE e ISAAR (CPF); níveis de descrição e, } \\
\text { indexação e linguagens documentárias; }\end{array}$ \\
\hline Elaborar resumos e índices & Resumos e índices: conceituação e elaboração; \\
\hline Aplicar a descrição arquivística & $\begin{array}{l}\text { Instrumentos de pesquisa: conceitos e objetivos; tipos } \\
\text { básicos: guias, inventários e catálogos e aplicação } \\
\text { prática da descrição arquivística. }\end{array}$ \\
\hline
\end{tabular}

Fonte: Adaptado do plano de ensino de Descrição Arquivística da UFSC, 2017.

A avaliação da disciplina na UFSC consistia em uma prova teórica, seminário e exercícios práticos. Como produto final, os estudantes deveriam desenvolver um instrumento de pesquisa, colocando em prática o seu. A frequência obrigatória era de $75 \%$ das aulas, com média mínima de 6,0. 
O curso de Arquivologia da Universidade Federal de Santa Catarina sofreu mudanças curriculares no ano de 2016, com a adoção de um novo currículo. Mas, como a disciplina era ofertada na 5a fase do curso, as alterações entraram em vigor em 2018.

Essa disciplina sofreu poucas modificações. Além da alteração do código da disciplina, a sua carga horária foi modificada. As aulas teóricas passaram de 41 h/a para 36 h/a e a de aulas práticas de $31 \mathrm{~h} / \mathrm{a}$ para $36 \mathrm{~h} / \mathrm{a}$. A disciplina passou a ser ministrada na 6a fase do curso. 0 conteúdo programático mantido e, foi incluída uma visita técnica. A disciplina passou a ter um pré-requisito, Classificação Arquivística.

O ensino da Descrição Arquivística nos cursos de Arquivologia da UdelaR e da UFSC tem semelhanças com relação à sua estrutura. Ambas buscam apresentar, conceituar e fundamentar a descrição com relação às teorias e metodologias que a norteiam. A seguir, apresentamos conteúdos da disciplina nas duas universidades. É possível perceber que a representação descritiva e os elementos de descrição são semelhantes. Outra semelhança é a apresentação das normas e padrões de descrição e a exploração dos instrumentos de pesquisa, visando sua aplicação prática.

Quadro 3 - Comparativo do ensino da descrição nos cursos de Arquivologia das Universidades em 2019

\begin{tabular}{|c|c|c|}
\hline CRITÉRIO & UdelaR & UFSC \\
\hline $\begin{array}{l}\text { Título da Unidade } \\
\text { Curricular/Disciplina }\end{array}$ & Descrição Documental & Descrição Arquivística \\
\hline Modalidade & Presencial & Presencial \\
\hline Período & Noturno & Matutino \\
\hline Semestre & 3o Semestre & 6o Semestre \\
\hline Carga-horária & $\begin{array}{l}120 \text { horas/aula, das quais: } 60 \text { horas } \\
\text { teórico-práticas, } 20 \text { horas de práticas } \\
\text { externas, } 35 \text { horas de trabalhos } \\
\text { domiciliares e } 5 \text { horas de preparação } \\
\text { expositiva. }\end{array}$ & $\begin{array}{l}72 \text { horas/aula, das quais: } 36 \text { horas } \\
\text { teóricas e } 36 \text { horas práticas. }\end{array}$ \\
\hline Pré-requisitos & $\begin{array}{l}\text { Introdução a Arquivologia e a Ciência } \\
\text { da Informação; Organização } \\
\text { Documental; Gestão Documental I. }\end{array}$ & Classificação Arquivística. \\
\hline Objetivos & $\begin{array}{l}\text { Proporcionar os fundamentos teóricos } \\
\text { e gerais do processo de descrição em } \\
\text { relação às outras funções } \\
\text { arquivísticas; } \text { reconhecer a } \\
\text { importância da normalização da } \\
\text { descrição para a elaboração de } \\
\text { instrumentos de pesquisa e; adquirir a } \\
\text { formação necessária para o } \\
\text { desenvolvimento de uma descrição } \\
\text { documental eficiente. }\end{array}$ & $\begin{array}{l}\text { Conhecer os fundamentos teóricos, } \\
\text { metodológicos e princípios norteadores } \\
\text { da descrição arquivística; conhecer os } \\
\text { elementos, níveis e instrumentos de } \\
\text { pesquisa aplicados à descrição } \\
\text { arquivística; conhecer as normas e } \\
\text { padrões da descrição arquivística; } \\
\text { elaborar resumos e índices e aplicar a } \\
\text { descrição arquivística. }\end{array}$ \\
\hline Avaliação & $\begin{array}{l}\text { Presença mínima de } 70 \% \text { e média } \\
\text { mínima (8) para a qualificação dos } \\
\text { exames parciais, assim como, a }\end{array}$ & $\begin{array}{l}\text { Presença mínima de } 75 \% \text { e média } \\
\text { mínima (6) para a aprovação na } \\
\text { disciplina, entre as formas de avaliação }\end{array}$ \\
\hline
\end{tabular}




\begin{tabular}{|l|l|l|}
\hline & realização de outras atividades & da disciplina estão: prova teórica, \\
& avaliativas como: controle de leituras, & seminário e exercícios práticos. Como \\
trabalhos extraclasse, participação em & trabalho final da disciplina os \\
& $\begin{array}{l}\text { aula, apresentação de seminários e } \\
\text { atividades práticas. }\end{array}$ & $\begin{array}{l}\text { estudantes precisam desenvolver um } \\
\text { instrumento de pesquisa. }\end{array}$ \\
\hline
\end{tabular}

Fonte: Adaptado dos plano de ensino de descrição dos cursos de Arquivologia da UdelaR e UFSC, 2019.

\section{Considerações finais}

A Descrição Arquivística é uma disciplina complexa que traz benefícios aos arquivos, arquivistas e usuários. Tornou-se objeto de normalização internacional a partir do ano de 2000. No Brasil sua normalização ocorreu em 2006 e no Uruguai em 2016. A busca por padrões e métodos de descrição favorece o desenvolvimento de instrumentos de pesquisa mais lógicos e eficazes aos arquivos, demandando dos arquivistas competências para a realização desse processo.

Essa disciplina pretende capacitar esses profissionais para a descrição e para o desenvolvimento de instrumentos de pesquisa e possibilita ao estudante o desenvolvimento de competências para tratar e descrever documentos de forma eficaz. Em um mundo globalizado, o arquivista deve estar preparado para o mundo do trabalho a nível regional e internacional, sendo necessário conhecimento das múltiplas normas que regem essa função arquivística.

Embora o ensino dessa disciplina tenha diferenças com relação à sua carga horária e conteúdo, identificaram-se algumas semelhanças entre os cursos dos dois países, no que concerne o seu conteúdo. A descrição enquanto método e atividade é uma atribuição do arquivista. Entretanto, essa função não está necessariamente vinculada À cultura onde está inserida.

Por meio da vivência em sala de aula nas duas universidades foi possível observar que a forma de ensinar a disciplina nos dois cursos é bastante semelhante. Essa semelhança deve ser um reflexo das normas internacionais de descrição e da regulamentação profissional. Além disso, acreditamos que o fato desses países serem próximos facilita essa semelhança. Ainda que em determinados aspectos relacionados à Arquivologia existam diferenças entre as duas instituições, foi possível notar muitas semelhanças na forma como a disciplina de Descrição Arquivística é ministrada nas duas universidades.

Os arquivistas devem ser capazes de realizar vários tipos de atividades, atividades essas, que valorizam esse profissional. Ademais, ele é imprescindível no tratamento documental. Esses são, sem dúvida, aspectos fundamentais para sua atuação no mundo do trabalho. 
Na realidade, o conhecimento do mundo do trabalho além das fronteiras locais, regionais e internacionais permite ampliar a experiência profissional. Além dos diversos contributos pessoais e profissionais, é possível identificar semelhanças e diferenças entre práticas e especificidades de cada um dos cursos. No nosso entender, o conhecimento da realidade de outros países contribui para fortalecer o sentido crítico dos profissionais bem como sua atuação.

Nota: O presente trabalho foi realizado com apoio da Coordenação de Aperfeiçoamento de Pessoal de Nível Superior - Brasil (CAPES) - Código de Financiamento 001.

\section{Referências}

ARQUIVO GERAL DA NAÇÃO (Uruguai). NUDA: Norma Uruguaia de Descrição Arquivística. Montevidéu: Arquivo Geral da Nação, 2016. 88 p. Disponível em:<http://www.agn.gub.uy/pdf/nudacontapa.pdf >. Acesso em: 20 jun. 2019.

ARQUIVO NACIONAL (Brasil). Dicionário Brasileiro de Terminologia Arquivística. Rio de Janeiro: Arquivo Nacional, 2005. $232 \quad$ p. $\quad$ Disponível em: http://www.arquivonacional.gov.br/images/pdf/Dicion_Term_Arquiv.pdf >. Acesso em: 20 jun. 2019.

BRASIL. Conselho Nacional de Arquivos. NOBRADE: Norma Brasileira de Descrição Arquivística. Rio de Janeiro: Arquivo Nacional, 2006.2 Disponível em:<http://conarq.arquivonacional.gov.br/images/publicacoes_textos/nobrade.pdf >. Acesso em: 20 jun. 2019.

CONSELHO INTERNACIONAL DE ARQUIVOS. ISAAR (CPF): Norma Internacional de Registro de Autoridade Arquivística para Entidades Coletivas, Pessoas e Famílias. 2. ed. Rio de Janeiro: Arquivo Nacional, 2004.2 Disponível em:<http://conarq.gov.br/images/publicacoes_textos/isaar_cpf.pdf > Acesso em: 20 jun. 2019.

CONSELHO INTERNACIONAL DE ARQUIVOS. ISAD(G): Norma Geral Internacional De Descrição Arquivística. 2. ed. Rio de Janeiro: Arquivo Nacional, 2000.Disponível em:<http://conarq.arquivonacional.gov.br/images/publicacoes_textos/isad_g_2001.pdf >. Acesso em: 20 jun. 2019.

CONSELHO INTERNACIONAL DE ARQUIVOS. ISDF: Norma Internacional para Descrição de Funções. 1. ed. Rio de Janeiro: Arquivo Nacional, 2008. Disponível em:<http://conarq.gov.br/images/publicacoes_textos/ISDF.pdf >. Acesso em: 20 jun. 2019.

CONSELHO INTERNACIONAL DE ARQUIVOS. ISDIAH: Norma Internacional para Descrição de Instituições com Acervo Arquivístico. 1. ed. Rio de Janeiro: Arquivo Nacional, 2009. Disponível em:<http://www.academia.org.br/sites/default/files/conteudo/norma_internacional_para_de scricao_de_instituicoes_com_acervo_arquivistico.pdf >. Acesso em: 20 jun. 2019.

DUFF, Wendy M. Mediação Arquivística. In: EASTWOOD, Terry; MACNEIL, Heather (Org.). Correntes atuais do pensamento arquivístico. Belo Horizonte: Ed. UFMG, 2016. 
LOPES, Luís Carlos. A informação e os arquivos: teorias e práticas. Niterói: Eduff, 1996. 142 p.

LOPEZ, André Porto Ancona. Como descrever documentos de arquivo: elaboração de instrumentos de pesquisa. São Paulo: Arquivo do Estado, Imprensa Oficial, 2002.

PETROCCELLI, Patricia Daniela. O ensino da biblioteconomia e arquivologia no Uruguai: evolução histórica. Ágora: arquivologia em debate, Florianópolis, v. 27, n. 54, p.33-45, jan./jun. 2017. Disponível em: <https://agora.emnuvens.com.br/ra/article/view/664/pdf >. Acesso em: 20 jun. 2019.

UNIVERSIDAD DE LA REPUBLICA. Licenciatura em Arquivologia. 2019. Disponível em:<http://www.fic.edu.uy/ensenanza/grado/lic-en-archivologia> Acesso em: 18 jun. 2019.

UNIVERSIDAD DE LA REPUBLICA. Plano de ensino de Descrição Documental. 2017.

UNIVERSIDAD DE LA REPUBLICA. Planos de ensino de Descrição Documental. 2019. Disponível em:<https://drive.google.com/open?id=1tVG-hWAxXjxINLQ9bYz4Mz4h7RJcbmOp>. Acesso em: 19 maio 2019.

UNIVERSIDADE FEDERAL DE SANTA CATARINA. Planos de ensino. 2017. Disponível em:<http://cin.ced.ufsc.br/planos-de-ensino-2017-1> Acesso em: 19 maio 2019.

UNIVERSIDADE FEDERAL DE SANTA CATARINA. Planos de ensino. 2019. Disponível em:<http://cin.ced.ufsc.br/planos-de-ensino-2017-1> Acesso em: 19 maio 2019.

UNIVERSIDADE federAL DE SANTA CATARINA. Projeto Pedagógico do Curso de Graduação Arquivologia da Universidade Federal de Santa Catarina. Disponível em:<http://arquivologia.ufsc.br/files/2016/05/PROJETO-PEDAG\%C3\%93GICO-DO-CURSOCurr\%C3\%ADculo-2010.1.pdf>. Acesso em: 19 maio 2019.

URUGUAY. Camara de Representantes. Arquivologia: reconhecimento de sua condição profissional e regulamentação de sua profissão. 2019. Disponível em:<https://www.aua.org.uy/sites/aua/files/Profesionalizaci\%C3\%B3n\%20Archiv\%C3\%B3logo s_0.pdf>. Acesso em: 2 jul. 2019.

URUGUAY. Lei n. 18.220, de 20 de dezembro de 2007. Dispõe sobre o Sistema Nacional de Arquivos. Disponível em:<https://docs.uruguay.justia.com/nacionales/leyes/ley-18220-dec-202007.pdf>. Acesso em: 20 jun. 2019.

URUGUAY. Lei n. 18.381, de 17 de outubro de 2008. Dispõe sobre o Direito de acesso à Informação Pública.

Disponível em:<http://archivo.presidencia.gub.uy/_web/leyes/2008/10/EC1028-00001.pdf>. Acesso em: 20 jun. 2019. 